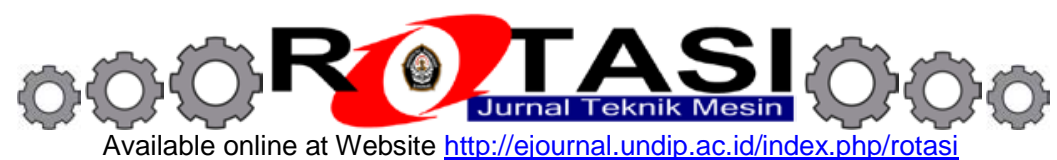

\title{
EVALUASI RENDAHNYA MAINTENANCE BETWEEN FAILURE (MTBF) PADA POMPA VERTIKAL
}

\author{
Norman Iskandar ${ }^{\mathrm{a}}$ * Restu Bagas Pangestu ${ }^{\mathrm{b}}$ \\ ${ }^{a}$ Dosen Program Studi S-1 Departemen Teknik Mesin, Fakultas Teknik, Universitas Diponegoro \\ ${ }^{\mathrm{b}}$ Mahasiswa Program Studi S-1 Departemen Teknik Mesin, Fakultas Teknik, Universitas Diponegoro \\ Jl. Prof. H. Soedarto, SH, Tembalang-Semarang 50725, Telp. +62247460059 \\ *E-mail: restubagas1993@gmail.com
}

\begin{abstract}
ABSTRAK
Untuk memproduksi bahan bakar minyak dan gas dibutuhkan peralatan-peralatan penunjang seperti turbin, tungku pembakaran, boiler, blower, pompa dan lain-lain. Peralatan-peralatan ini harus dalam kondisi prima karena tanpa peralatan ini produksi tidak dapat berjalan. Peralatan-peralatan ini harus memiliki kehandalan, efisiensi dan ketahanan yang baik. Untuk menujang hal tersebut dibutuhkan riset, analisa serta manajemen perawatan yang baik. Salah satu peralatan dalam dunia industri MIGAS adalah pompa sentrifugal dengan poros vertikal atau sering disebut pompa vertikal. Pada kasus pompa vertikal ini digunakan untuk mengalirkan slop oil dari CDU (Crude Distillation Unit) dan ARHDM (Atmospheric Residue Hydrodemetalizzation) menuju RCC (Residue Catalytic Cracking). Pada penggunaan pompa vertikal sering terjadi rendahnya anatara waktu pemakaian dengan perawatan yang telah ditentukan atau yang disebut rendahnya MTBF (maintenance time between failure). Pompa vertikal yang seharusnya dilakukan preventive maintenace setahun sekali tetapi sudah mengalami kerusakan sebelum satu tahun. Penelitian ini bertujuan untuk mengetahui rendahnya MTBF dan terjadinya kegagalan. Metode yang dilakukan analisa $N P S H_{A}$ dan $N P S H_{R}$ antara sumur dan pompa dengan temperatur $40^{\circ} \mathrm{C}$ dan $50^{\circ} \mathrm{C}$ serta analisa tinggi fluida dan panjang poros. Untuk analisa $N P S H_{A}$ dan $N P S H_{R}$ bertujuan apakah nilai $N P S H_{A}$ lebih besar dari $N P S H_{R}$. Sedangkan analisa tinggi fluida dan panjang poros bertujuan apakah pompa vertikal memiliki lowest allowable liquid level yang diizinkan. Lowest allowable liquid level merupakan batas toleransi tinggi fluida didalam sumur terhadap impeller agar impeller tetap terendam fluida. Dari hasil perhitungan dan analisa bahwa nilai $\mathrm{NPSH}_{A}>\mathrm{NPSH}_{R}$ dengan nilai untuk temperatur $40^{\circ} \mathrm{C}$ adalah 9,42 meter dan pada temperatur $50^{\circ} \mathrm{C}$ adalah 9,02 meter. Untuk pompa vertikal yang memiliki lowest allowable liquid level diluar dibawah standar impeller mengalami kavitasi ringan
\end{abstract}

Kata kunci: Maintenace, Pompa vertikal , $N P S H_{A}, N P S H_{R}$, Analisa kegagalan.

\section{PENDAHULUAN}

Pompa vertikal merupakan salah satu alat yang penting di dunia industri. Fungsi alat ini adalah untuk mengalirkan fluida dari tekanan tinggi ke tekanan yang rendah. Pada industri migas pompa vertikal berfungsi untuk mengalirkan hasil pengolahan minyak mentah dari satu unit ke unit lain. Untuk mengalirkan fluida dari unit tersebut rata-rata pompa vertikal mengalirkan fluida hasil pengolahan dengan beban fluida sebanyak $125 \mathrm{~m}^{3}$ dengan suhu yang bervariasi di setiap unitnya. Pompa vertikal pada industri migas bekerja selama 24 jam karena permintaan produk yang sangat tinggi. Karena beban kerja yang tinggi pompa vertikal ini harus memiliki kehandalan dan reabilitas yang tinggi.

Karena beban kerja yang berat pompa vertikal sering kali mengalami kegagalan. Kegagalan tersebut biasanya karena terjadi kavitasi, batas lowest allowable liquid level yang tidak sesuai, dll. Penyebab kegagalan tersebut dapat mengakibatkan kavitasi, terjadinya jarak waktu perawatan (maintenace time between failure) yang rendah sehingga mengeluarkan biaya yang lebih untuk perawatan. Untuk mengetahui rendahnya Maintenace time between failure (MTBF) yang rendah dilakukan penelitian.

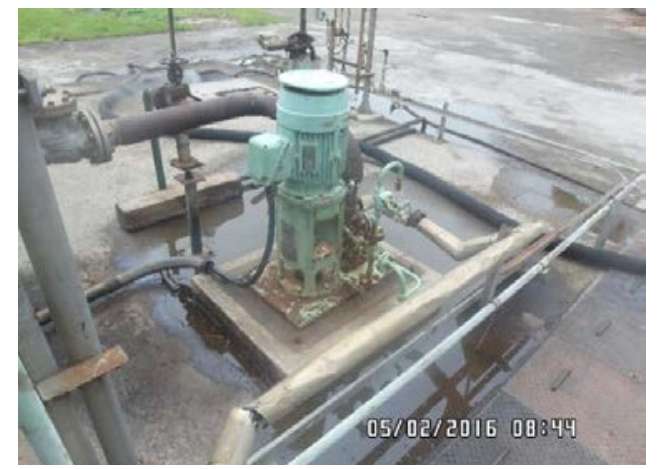

Gambar 1. Pompa pada saat terpasang. 
Penelitian ini memiliki tujuan untuk mengetahui penyebab rendahnya MTBF (maintenance time between failure). Untuk mencapai tujuan tersebut maka dilakukan penelitian dengan menganalisa perbandingan antara besar $N P S H_{A}$ dengan $N P S H_{R}$ dan analisa tinggi fluida dengan panjang poros. Analisa perbandinganan $N P S H_{A}$ dengan $N P S H_{R}$ bertujuan apakah $N P S H_{A}$ lebih bear dari $N P S H_{R} . N P S H_{A}$ merupakan head yang disediakan sumur untuk pompa dan $N_{R S} H_{R}$ adalah head yang dimiliki pompa tersebut. Karena syarat dari sistem pemompaan agar pompa tidak mengalami kegagalan adalah $N_{P S H}$ lebih besar dari $N P S H_{R}$. Analisa tinggi fluida dengan panjang poros bertujuan untuk mengetahui apakah pompa vertikal memiliki nilai lowest allowable liquid level yang masih sesuai atau tidak. Lowest allowable liquid level merupakan batas toleransi tinggi fluida didalam sumur terhadap impeller agar impeller tetap terendam fluida agar.

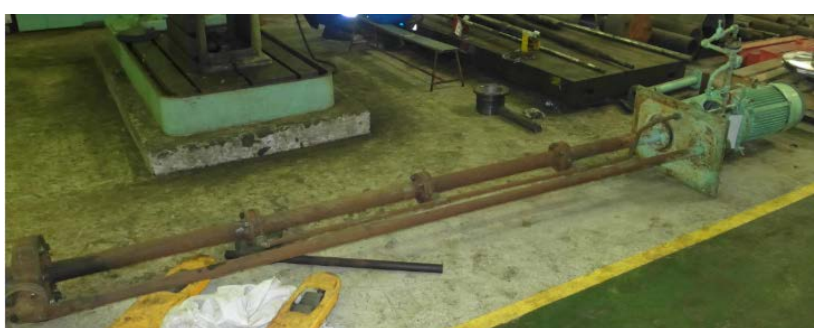

Gambar 2. Pompa vertikal pada saat diangkat dari sumur.

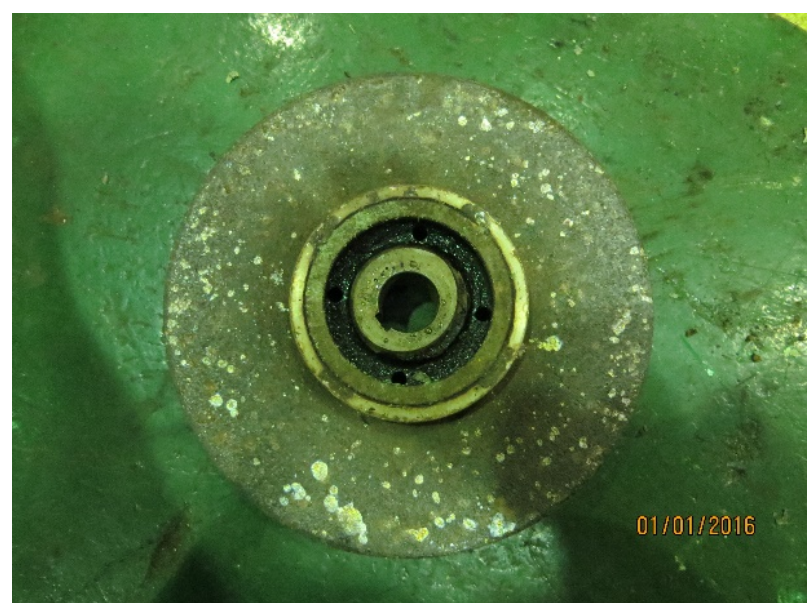

Gambar 3. Impeller yang mengalami kavitasi ringan.

\section{METODOLOGI}

\subsection{Metode Analisa}

Evaluasi rendahnya MTBF dilakukan untuk mengurangi waktu perawatan pompa yang berada dibawah waktu standar. Evaluasi ini dilakukan dua analisa. Analisa pertama yaitu membandingkan besarnya $\mathrm{NPSH}_{\mathrm{A}}$ terhadap $\mathrm{NPSH}_{\mathrm{R}}$. Analisa yang pertama bertujuan apakah $\mathrm{NPSH}_{\mathrm{A}}>\mathrm{NPSH}_{\mathrm{R}}$ atau tidak. Analisa yang kedua Analisa Tinggi Fluida dan Panjang Poros. Analisa tinggi fluida dan panjang poros bertujuan untuk mengetahui apakah nilai lowest allowable liquid level masih sesuai atau tidak.

Pada Analisa yang pertama fluida slop oil yang memiliki spesific gravity 0,835 dan air dengan spesific gravity 1 karena di dalam sumur terdapat dua fluida. Fluida yang di analisa adalah air karena air memmiliki spesific gravity yang lebih tinggi untuk mengetahui pada saat spesific gravity maksimal. Pada analisa yang kedua dilakukan dengan cara analisa malalui data sheet dari perusahaan dan analisa dengan perhitungan aktual.

\subsection{Mencari NPSH}

$\mathrm{NPSH}_{\mathrm{A}}$ adalah head pada sisi hisap pompa dimana head pada sisi hisap pompa berada diatas tekanan uap jenuh fluida [4]. Dalam hal ini pompa yang menghisap dari tempat terbuka dengan tekanan atmosfer pada permukaan zat cair, NPSH yang tersedia dapat ditulis sebagai berikut [4].

$\mathrm{NPSH}_{A}=\mathrm{Ha} \pm \mathrm{Hs}-\mathrm{Hvp}-\mathrm{Hf}-\mathrm{Hi}$

Ha merupakan tekanan atmosfer tekanan atmosfer diatas permukaan laut menurut ketinggian. Hs merupakan Tinggi dari centerline suction pompa ke level fluida. Hvp merupakan head yang dikalkulasi dengan memantau temperatur fluida. Hf merupakan kerugian head sepanjang pipa hisap. Hi merupakan kehilangan energi yang terjadi pada leher suction pompa. Pada kasus ini Hi di abaikan karena nilainya yang sangat kecil 


\section{3. $\quad \mathrm{NPSH}_{\mathrm{R}}$}

$\mathrm{NPSH}_{\mathrm{R}}$ adalah head pada sisi hisap pompa yang terletak pada centerline impeller diatas tekanan uap jenuh fluida [4]. Nilai $\mathrm{NPSH}_{\mathrm{A}}$ pompa dari pabrikan adalah 2,44 meter. $\mathrm{NPSH}_{\mathrm{A}}$ sama dengan jumlah tekanan dinamis atau tinggi kecepatan pada permukaan sudu dan semua kerugian aliran antara flens hisap dan permulaan sudu. Kerugian aliran dan kecepatan aliran volume (Q) dan dari jumlah putaran (ns) akan tetapi kerugian aliran dan kecepatan aliran tersebut tergantung pula dari bentuk sudu, jumlah sudu, tebal sudu, besarnya lubang laluan, dan unsur-unsur konstruksi yang lain.

\section{HASIL DAN PEMBAHASAN}

Data yang digunakan diambil dari data sheet dan hasil pengukuran aktual. Berikut adalah analisa besarnya $\mathrm{NPSH}_{\mathrm{A}}$ terhadap $\mathrm{NPSH}_{\mathrm{R}}$ dan Analisa Tinggi Fluida dan Panjang Poros.

\subsection{Analisa Besarnya $\mathrm{NPSH}_{\mathrm{A}}$ terhadap $\mathrm{NPSH}_{\mathrm{R}}$}

Tabel 1. Spesifikasi pompa [2].

\begin{tabular}{ccc}
\hline No & Spesifikasi & Besar \\
\hline 1 & RPM $(\mathrm{rad} / \mathrm{min})$ & 2915 \\
2 & Minimal continuous flow $\left(\mathrm{m}^{3} / \mathrm{hr}\right)$ & 5 \\
3 & Maximum differential head $(\mathrm{m})$ & 62,7 \\
4 & Maximum disch flange suction pressure $\left(\mathrm{kg} / \mathrm{cm}^{3} \cdot \mathrm{g}\right)$ & 6,9 \\
5 & $\mathrm{NPSH}_{\mathrm{R}}(\mathrm{m})$ & 2,44 \\
\hline
\end{tabular}

Tabel 2. Spesifikasi fluida pada sumur [2].

\begin{tabular}{ccc}
\hline No & Spesifikasi & Besar \\
\hline 1 & Spesific gravity air & 1 \\
2 & Spesific gravity slop oil & 0,835 \\
3 & Temperatur fluida $\left({ }^{\circ} \mathrm{C}\right)$ & $40-50$ \\
\hline
\end{tabular}

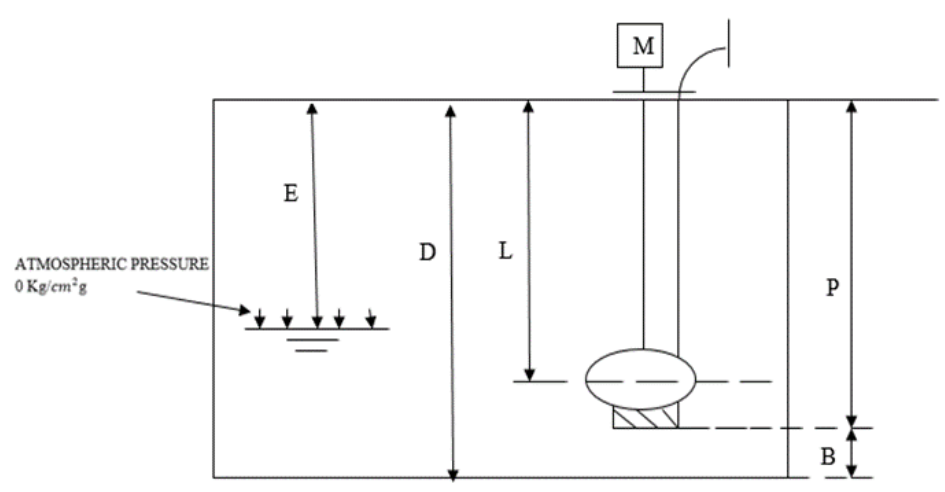

Gambar 4. Desain Ukuran Sumur dan Pompa.

\begin{tabular}{|c|c|c|}
\hline $\mathrm{L}$ & : panjang poros pompa dari atas sumur ke impeller & $=4,65 \mathrm{~m}$ \\
\hline $\mathrm{D}$ & : kedalaman sumur & $=4,975 \mathrm{~m}$ \\
\hline $\mathrm{P}$ & : kedalaman sumur sampai ujung pompa & $=4,875 \mathrm{~m}$ \\
\hline $\mathrm{E}$ & : ketinggian terendah fluida yang diizinkan & $=4,595 \mathrm{~m}$ \\
\hline B & : kedalaman dari ujung pompa ke dasar sumur & $=0.1 \quad \mathrm{~m}$ \\
\hline Friction loss (Hf) & & $=0,095 \mathrm{~m}$ \\
\hline
\end{tabular}

\subsection{Perhitungan Nilai $\mathrm{NPSH}_{\mathrm{A}}$ terhadap $\mathrm{NPSH}_{\mathrm{R}}$}

Pada perhitunagan $N P S H_{A}$ berikut fluida slop oil diganti dengan air karena spesific gravity dari air tidak jauh berbeda dan lebih berat. Apabila menggunakan spesific gravity air pemopaan dapat dilakukan secara otomatis jika kita menggunakan fluida slop oil juga dapat dilakukan pemompaan. Pada saat dilapangan fluida memiliki temperatur $40^{\circ} \mathrm{C}$ dan $50^{\circ} \mathrm{C}$. Spesific gravity air adalah 1 sedangkan spesific grafity dari slop oil adalah 0,835 .

Untuk tekanan atmosfer (Ha) dengan besar $0 \mathrm{Kg} / \mathrm{cm}^{2}$ g maka barometrik air menurut ketinggian adalah 10,33 $\mathrm{m}$. untuk barometrik air menurut ketinggian dapat dilihat di tabel 3 Untuk nilai Hvp dapat dilihat pada tabel 4. 
Tabel 3. Tekanan atmosferik menurut ketinggian [1].

\begin{tabular}{|c|c|c|}
\hline No. & Ketinggian terhadap permukaan laut $\left(\frac{\mathrm{kg}}{\mathrm{cm} \cdot \mathrm{g}}\right)$ & Tekanan atmosfir dalam ketinggian (meter) \\
\hline 1 & $-304,8$ & 10,73 \\
\hline 2 & $-152,4$ & 10,55 \\
\hline 3 & 0 & 10,33 \\
\hline 4 & 152,4 & 10,15 \\
\hline 5 & 304,8 & 10 \\
\hline 6 & 457,2 & 9,78 \\
\hline 7 & 609,6 & 9,60 \\
\hline 8 & 762 & 9,45 \\
\hline 9 & 914,4 & 9,26 \\
\hline 10 & 1066,8 & 9,08 \\
\hline 11 & 1219,2 & 8,90 \\
\hline 12 & 1371,6 & 8,78 \\
\hline 13 & 1524 & 8,60 \\
\hline 14 & 1676,4 & 8,41 \\
\hline 15 & 1828,8 & 8,29 \\
\hline 16 & 1981,2 & 8,14 \\
\hline 17 & 2133,6 & 7,98 \\
\hline 18 & 2286 & 7,83 \\
\hline 19 & 2438,4 & 7,68 \\
\hline 20 & 2590,8 & 7,53 \\
\hline 21 & 2743,2 & 7,41 \\
\hline 22 & 2895,6 & 7,25 \\
\hline & & \\
\hline
\end{tabular}

Tabel 4. Tinggi absolut air dalam variasi temperatur [1]

\begin{tabular}{|c|c|c|}
\hline No. & Temperatur $\left(o_{C}\right)$ & Tinggi $(\mathrm{m})$ \\
\hline 1 & 4,4 & 0,09 \\
\hline 2 & 10,0 & 0,12 \\
\hline 3 & 15,6 & 0,18 \\
\hline 4 & 21,1 & 0,25 \\
\hline 5 & 26,7 & 0,54 \\
\hline 6 & 32,2 & 0,49 \\
\hline 7 & 37,8 & 0,67 \\
\hline 8 & 48,9 & 1,19 \\
\hline 9 & 60,0 & 2,03 \\
\hline 10 & 71,1 & 3,23 \\
\hline 11 & 82,2 & 5,28 \\
\hline 12 & 93,3 & 8,12 \\
\hline 13 & 100 & 10,35 \\
\hline 14 & 104,4 & 12,10 \\
\hline 15 & 115,6 & 17,59 \\
\hline 16 & 126,7 & 24,93 \\
\hline 17 & 137,8 & 34,64 \\
\hline 18 & 148,9 & 47,18 \\
\hline
\end{tabular}

- Nilai Hvp untuk temperatur $40^{\circ} \mathrm{C}$ didapat dengan cara interpolasi sebagai berikut :

Untuk mencari $\mathrm{NPSH}_{A}$ digunakan persamaan [1]. Pertama cari nilai Ha dengan dengan melihat tabel 3. Nilai Ha yang diambil yaitu ketika tekanan atmosfer diatas permukaan laut adalah $0 \frac{\mathrm{kg}}{\mathrm{cm}^{2} \cdot \mathrm{g}}$. Tekanan atmosfer sumur dianggap berada $0 \frac{\mathrm{kg}}{\mathrm{cm}^{2} \cdot \mathrm{g}}$ diatas permukaan laut dengan nilai ketinggian 10,33 m. Selanjutnya mencari nilai $H_{v p}$ dengan menginterpolasikan tabel 4 sehingga mendapat tinggi absolut pada $40^{\circ} \mathrm{C}$ dan $50^{\circ} \mathrm{C}$ dan didapat tinggi absolutnya 0.76 meter dan 1.27 meter. Selanjutnya mencari nilai Hs dengan melihat dari gambar 4 dengan mengurangi ketinggian terendah fluida yang diizinkan dengan nilai panjang poros pompa dari atas sumur ke impeller dengan nilai 0.005 meter. Nilai Hf untuk kasus ini diabaikan karena terlalu kecil sehingga tidak berpengaruh. Setelah mendapat nilai Ha, Hs dan $H_{v p}$ maka d masukan ke persasmaan (1) dan didapat nilai 9.42 meter untuk fluida dengan temperatur $40^{\circ} \mathrm{C}$ dan 9.02 meter untuk fluida dengan temperatur $50^{\circ} \mathrm{C}$. Maka perbandingan $N P S H_{A}$ dan $N P S H_{R}$ untuk temperatur $40^{\circ} \mathrm{C}$ dan $50^{\circ} \mathrm{C}$ 


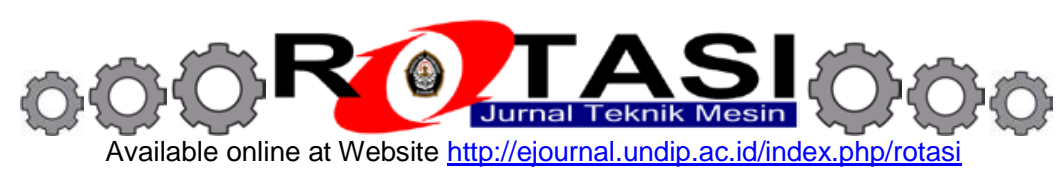

adalah $\mathrm{NPSH}_{A}>\mathrm{NPSH}_{R}$. Kedua $\mathrm{NPSH}_{A}$ ternyata lebih besar dari $\mathrm{NPSH}_{R}$ sehingga nilai $\mathrm{NPSH}_{A}$ bukan penyebab rendanya $\mathrm{MTBF}$.

\subsection{Analisa Tinggi Fluida dan Panjang Poros}

analisa tinggi fluida dan panjang poros dilakukan untuk mengetahui tinggi minimum fluida pada sumur serta letak transmiter. Transmiter ini digunakan untuk memberi tanda bahwa fluida telah berada pada titik terendah yang yang diizinkan. Transmiter yang digunakan adalah 15-LT-306 dengan range pembacaan dari 0 1,62 m.

\subsubsection{Analisa Tinggi Fluida dan Panjang Poros Dengan Menggunakan Data Sheet}

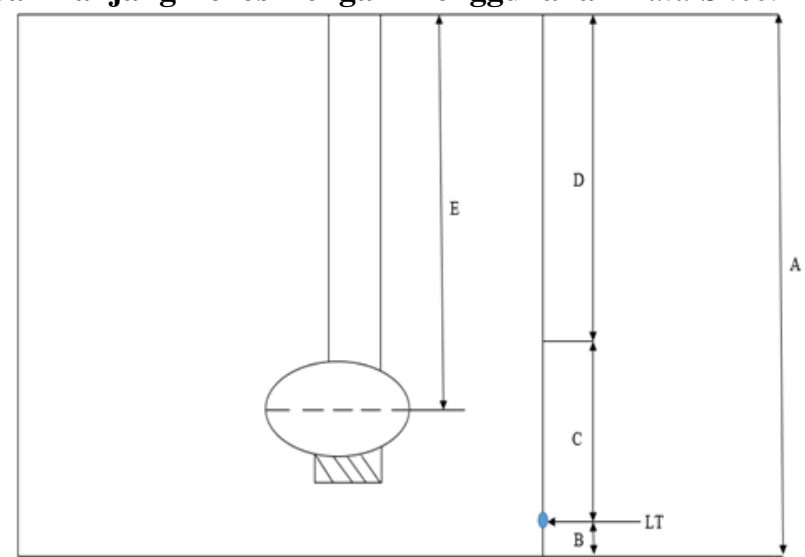

Gambar 5. Skema Panjang Sumur, Pompa dan Transmiter
A $\quad=$ kedalaman sumur
$\mathrm{B} \quad=$ tinggi transmiter dari dasar sumur
$=4,975 \mathrm{~m}$
$=0,2 \mathrm{~m}$
$\mathrm{D} \quad$ = tinggi fluida minimal dari atas sumur
$=1,82 \mathrm{~m}$
= panjang poros hingga impeller pompa dari dasar sumur
$=3,16 \mathrm{~m}$

LT $=$ Transmiter

Dari data sketch diatas diketahui tidak ada permasalahan antara panjang poros, tinggi fluida dan peletakan transmiter. Pada sketch diatas peletakan transmiter telah diletakan pada posisi yang sesuai sehingga impeller tetap terendam fluida pada saat batas terendah transmiter transmiter.

\subsubsection{Analisa Tinggi Fluida dan Panjang Poros Dengan Menggunakan Pengukuran Aktual}

Dari data sheet ternyata tidak terjadi masalah. Untuk mengetahui hasil yang lebih akurat maka dilakukan pengukuran langsung dari panjang poros. Pengukuran langsung ini bertujuan untuk membandingkan antara perhitungan data sheet dengan perhitungan aktual. berikut data sheet setelah pengukuran aktual.

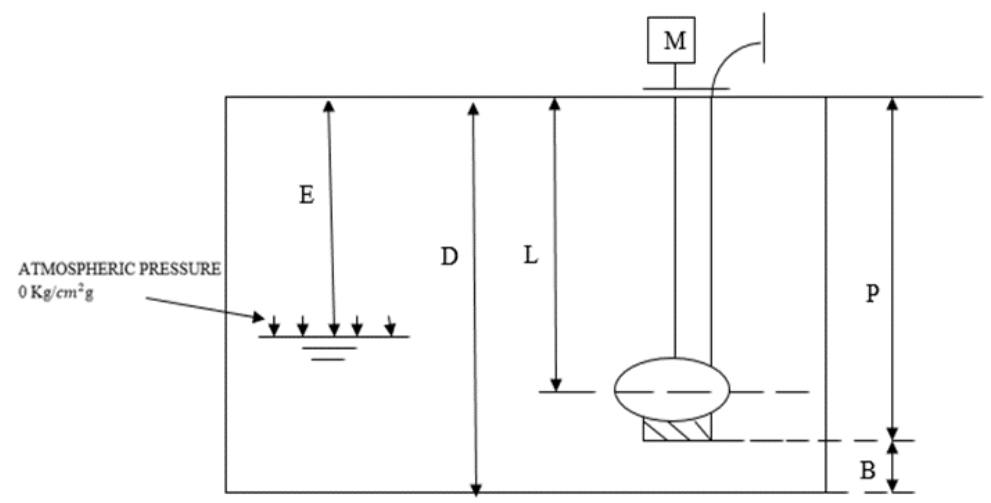

Gambar 6. Data Sheet Pengukuran poros pompa aktual

L : panjang poros pompa dari atas sumur ke impeller

$=3,05 \mathrm{~m}$

D : kedalaman sumur

$=4,975 \mathrm{~m}$

$\mathrm{P} \quad$ : kedalaman sumur sampai ujung pompa

$=3,275 \mathrm{~m}$

E : ketinggian terendah fluida yang diizinkan

$=4,595 \mathrm{~m}$

B : kedalaman dari ujung pompa ke dasar sumur

$=0.1 \mathrm{~m}$ 
Setelah dilakukan perhitungan aktual dengan menghitung langsung desain pompa terhadap sumur dan transmiter ternyata panjang poros hingga impeller pompa memiliki panjang 3,05 meter sedangkan desain pada data sheet panjangnya 4,65 meter. Pemendekan ini berpengaruh besar pada sistem pelumasan pompa. Tinggi fluida minimal yang diizinkan adalah 4,595 meter sedangkan biasanya penghentian pengorasian pompa berhenti pada ketinggian fluida 4,07 meter dari atas sumur. Dengan demikian pompa dapat mengalami kavitasi dan impeller terlumasi dan tidak ada fluida yang dipompa sehingga mengakibatkan kegagalan.

\section{KESIMPULAN}

Nilai $N_{P S H_{A}}$ pada sumur pompa sangat jauh lebih tinggi. Sehingga $N P S H_{A}$ bukan penyebab utama terjadinya kegagalan. Pada temperatur $40^{\circ} \mathrm{C} \mathrm{NPSH}$ memiliki nilai 9,42 m sedangkan pada saat temperatur $50^{\circ} \mathrm{C} N P S H_{A}$ Memiliki nilai 9,02 m. Dari data hasil perhitungan maka $\mathrm{NPSH}_{A}$ bukan penyebab terjadinya MTBF.

Dari hasil analisa Analisa Tinggi Fluida dan Panjang Poros ternyata pompa mengalami kegagalan karena berubahnya panjang poros yang tidak diketahui karena pada saat pemendekan poros tidak tercatat. Akibatnya pada saat dipompa fluida di dalam sumur akan berkurang sedangkan transmiter yang digunakan untuk panjang poros ke impeller dengan panjang 4,65 meter digunakan untuk panjang poros ke impeller dengan panjang 3,05 meter sehingga pada saat fluida mencapai batas terendah pompa dapat mengalami kavitasi dan impeller dapat tidak terendam oleh fluida yang berfungsi sebagai plumas. Rendahnya MTBF dan kavitasi ringan pun terjadi karena impeller tidak terlumasi secara sempurna

\section{REFERENSI}

[1] Anonymous, 1889, Tables, “Formulae and Piping Wiring Diagrams”, Skidmore, Benton Harbour,

[2] Data sheet pompa 15-P-902 PT. Pertamina RU-VI Balongan

[3] EagleBrugmenn Group, 2014, “API 682 4th Edition Piping Plans”, EagleBrugmenn Germany GmbH \& Co. KG. Germany.

[4] Volk, M., 2005, “Pump Characteristics and Applications 2nd Edition”. Taylor and Francis Group. Boca Raton. 